\title{
SURVEY OF EUROPEAN PROGRAMMES FOR THE EPIDEMIOLOGICAL SURVEILLANCE OF CONGENITAL TOXOPLASMOSIS
}

\author{
A Bénard (antoine.benard@isped.u-bordeaux2.fr)1,2,3, E Petersen ${ }^{4}$, R Salamon ${ }^{1,2,3}$, G Chêne ${ }^{1,2,3}$, Ruth Gilbert ${ }^{5}$, L R Salmi ${ }^{1,2,3}$, \\ for the European Toxo Prevention Study Group (EUROTOXO) \\ 1. Institut national de la santé et de la recherche médicale (National institute of health and medical research, INSERM), U897, \\ Bordeaux, France \\ 2. University Victor Segalen Bordeaux 2, School of Public Health, Bordeaux, France \\ 3. Centre Hospitalier Universitaire de Bordeaux, Bordeaux, France \\ 4. Statens Serum Institut, Copenhagen, Denmark \\ 5. Institute of Child Health, London, United Kingdom
}

The objective of this investigation was to describe systems for the epidemiological surveillance of congenital toxoplasmosis implemented in European countries. In September 2004, a questionnaire, adapted from the evaluation criteria published by the United States Centers for Disease Control and Prevention, was sent to a panel of national correspondents in 35 countries in the European geographical area with knowledge of the epidemiological surveillance systems implemented in their countries. Where necessary, we updated the information until July 2007. Responses were received from 28 countries. Some 16 countries reported routine surveillance for toxoplasmosis. In 12 countries (Bulgaria, Cyprus, Czech Republic, England and Wales, Estonia, Ireland, Latvia, Lithuania, Malta, Poland, Scotland and Slovakia), surveillance was designed to detect only symptomatic toxoplasmosis, whether congenital or not. Four countries reported surveillance of congenital toxoplasmosis, on a regional basis in Italy and on a national basis in Denmark, France and Germany. In conclusion, epidemiological surveillance of congenital toxoplasmosis needs to be improved in order to determine the true burden of disease and to assess the effectiveness of and the need for existing prevention programmes.

\section{Introduction}

Toxoplasmosis is caused by a protozoan parasite (Toxoplasma gondii). While toxoplasmosis infection is often benign, congenital toxoplasmosis (transmission to the foetus when a pregnant woman acquires toxoplasma infection for the first time during pregnancy) can lead to severe sequelae for the foetus and the newborn with visual or neurological impairment or death.

It is important to evaluate the burden of toxoplasma infection in the general population, as well as in pregnant women, foetuses, newborns and children, because this contributes to the rationale behind the different screening programmes currently performed (none, prenatal or postnatal) [1-3]. Frequency and severity of a disease are the basic measurements used to assess its burden, and data on this can be collected in specific studies or surveillance systems. The value of epidemiological surveillance is that it can be used to monitor trends over time. Public health strategies to prevent congenital toxoplasmosis differ between European countries. It is still being debated which are the best methods for controlling congenital toxoplasmosis, and the debate is not always based on accurate information.

The EUROTOXO project (http://eurotoxo.isped.u-bordeaux2.fr) is a European consensus initiative aimed at defining the implications of current scientific knowledge for a research agenda and for policy decisions on how best to prevent congenital toxoplasmosis and its consequences. The project has reviewed the state of the knowledge concerning the burden of toxoplasma infection in Europe. This article presents a systematic review of the systems implemented in European countries for the epidemiological surveillance of toxoplasmosis.

\section{Methods}

\section{Source of information}

We identified contacts for national surveillance programmes in 30 European countries (Table 1) from the following sources:

- the members of the Eurosurveillance Editorial Board listed on the Eurosurveillance website at the time;

- the Inventory of Resources for Infectious Diseases in Europe (IRIDE) (http://iride.cineca.org/public/invcountries.html);

- the European Programme for Intervention Epidemiology Training (EPIET) network (http://www.epiet.org/).

Contacts for six other European countries (Albania, BosniaHerzegovina, Bulgaria, Croatia, Macedonia, and Serbia-Montenegro) were identified by Google search.

We did not find correspondents for Andorra, Monaco or Northern Ireland. The list of correspondents is shown in Table 1. All contacts were sent emails in September 2004 and those who did not respond were sent three further emails in January/February, April, and July 2005. We maintained contact with our correspondents in each participating countries until July 2007 and updated the data when a change in the surveillance systems was signalled. This was the case for France (implementation of a new surveillance system) and Denmark (surveillance system stopped).

\section{Data collection and interpretation}

We developed a comprehensive questionnaire, based on the criteria published by the United States' (US) Centers for Disease Control and Prevention (CDC) for the evaluation of epidemiological 
TA B L E 1

European correspondents contacted to participate in the survey on the epidemiological surveillance of toxoplasmosis

Countries that participated in the survey

\begin{tabular}{|c|c|}
\hline Austria & Reinhild Strauss, Federal Ministry for Health, Family and Youth, General Directorate of Public Health, Vienna \\
\hline Belgium & $\begin{array}{l}\text { Germaine Hanquet, Scientific Institute for Public Health, Unit of Epidemiology, Ministry of Social Affairs, Public Health and Environment, } \\
\text { Brussels }\end{array}$ \\
\hline $\begin{array}{l}\text { Bosnia and } \\
\text { Herzegovina }\end{array}$ & Semra Cavaljuga, Institute for Epidemiology and Biostatistics, School of Medicine, University of Sarajevo, Sarajevo \\
\hline Bulgaria & Mira Kojuharova, National Centre of Infectious and Parasitic Diseases, Department of Epidemiology, Sofia \\
\hline Cyprus & $\begin{array}{l}\text { Olga Kalakouta, on behalf of Dr. Chrystalla Hadjianastassiou, Chief medical Officer, Medical and Public Health Services, Ministry of } \\
\text { Health, Nicosia }\end{array}$ \\
\hline Czech Republic & Petr Kodym, National Reference Laboratory for Toxoplasmosis, National Institute of Public Health, Prague \\
\hline Denmark & Henrik Vedel Nielsen, Unit for Mycology and Parasitology, Statens Serum Institut, Copenhagen \\
\hline England and Wales & Robert Smith, Public Health Laboratory, Service of Communicable Disease, Surveillance Centre Wales, Cardiff \\
\hline Estonia & Kuulo Kutsar, Department of Communicable Diseases, Health Protectorate Inspectorate, Tallinn \\
\hline Finland & Maija Lappalainen, Department of Virology, Hospital District of Helsinki and Uusimaa, Helsinki \\
\hline France & $\begin{array}{l}\text { Isabelle Villena, National Reference centre for toxoplasmosis, Reims; Véronique Goulet, Department of Infectious Diseases, Institut de } \\
\text { Veille Sanitaire, Saint-Maurice }\end{array}$ \\
\hline Germany & $\begin{array}{l}\text { Katharina Alpers, Department for Infectious Disease Epidemiology, Gastrointestinal Infections, Zoonoses and Tropical Infections, Robert } \\
\text { Koch Institute, Berlin }\end{array}$ \\
\hline Greece & $\begin{array}{l}\text { Yanis Tselentis, Laboratory of Clinical Bacteriology, Parasitology, Zoonoses and Geographical Medicine, University of Crete, Faculty of } \\
\text { Medicine, Heraklion }\end{array}$ \\
\hline Ireland & Darina o'Flanagan, HSE-Health Protection Surveillance Centre, Dublin \\
\hline Italy & $\begin{array}{l}\text { Wilma Buffolano, Perinatal Infection Unit, Department of Paediatrics, Federico II University of Naples; Maria Grazia Pompa, } \\
\text { Communicable Disease Unit, DG Health Prevention, Ministry of Health, Rome }\end{array}$ \\
\hline Latvia & Irina Lucenko, Division of Epidemiology of Infectious Diseases, State Public Health Agency, Riga \\
\hline Lithuania & Bronius Morkunas, Centre for Communicable Disease Prevention and Control, Vilnius \\
\hline Malta & Tanya Melillo Fenech, Disease Surveillance Unit, Department of Public Health, Ministry of Health, Msida \\
\hline Netherlands & $\begin{array}{l}\text { Laetitia M. Kortbeek, Diagnostic Laboratory for Infectious Diseases and Perinatal Screening (LIS), National Institute of Public Health and } \\
\text { the Environment, Bilthoven }\end{array}$ \\
\hline Norway & Hans Blystad, Department of Infectious Disease Epidemiology, Norwegian Institute of Public Health, Oslo \\
\hline Poland & Malgorzata Sadkowska-Todys, Laboratory of Zoonoses, Department of Epidemiology, National Institute of Hygiene, Warsaw \\
\hline Portugal & Judite Catarino, General Health Directorate, Lisbon \\
\hline Romania & $\begin{array}{l}\text { Adriana Pistol, General Department of Public Health, Service of Prevention and Control of Communicable Diseases, Ministry of Health and } \\
\text { Family, Bucharest }\end{array}$ \\
\hline Scotland & Lynda Browning, Zoonoses Section, Health Protection Scotland, Glasgow \\
\hline Slovakia & Maria Avdicova, Department of Epidemiology, Regional Institute of Public Health, Baska Bystrica \\
\hline Slovenia & Jernej Logar, Institute of Microbiology, Medical Faculty, Ljubljana \\
\hline Sweden & Johan Lindh, Department of Parasitology, Mycology and Water, Swedish Institute for Infectious Disease Control, Solna \\
\hline Switzerland & $\begin{array}{l}\text { Karim Boubaker, Infectious Diseases Section, Division of Communicable Diseases, Swiss Federal of fice of Public Health, Public Health } \\
\text { Direction, Bern }\end{array}$ \\
\hline & Countries that were asked but did not participate in the survey \\
\hline Albania & Eduard Kakarriqi, Department of Epidemiology, Institute of Public Health, Rruga \\
\hline Croatia & Ira Gjenero-Margan, Croatian Public Health Institute, Department of Epidemiology of Infectious Diseases, Zagreb \\
\hline Hungary & Márta Melles, 'Johan Béla' National Centre for Epidemiology, Budapest \\
\hline Luxembourg & Robert Hemmer, National Service of Infectious Diseases, Centre Hospitalier de Luxembourg, Luxembourg \\
\hline Macedonia & $\begin{array}{l}\text { Kristin Vasilevska, Medical Faculty Skopje, University ‘Sv. Kiril i Metodij’ } \\
\text { Institute of Epidemiology, Biostatistics and Medical Informatics, Skopje }\end{array}$ \\
\hline Spain & $\begin{array}{l}\text { Luiza Sanchez Serrano, Sección de Sistema de Información Microbiológica, Vigilancia de Salud Pública, National Centre of Edpidemiology, } \\
\text { Hospital Carlos III, Madrid }\end{array}$ \\
\hline Serbia-Montenegro & Danica Masanovic, Sanitary Inspection of the Ministry of Health of Montenegro, Podgorica \\
\hline
\end{tabular}


surveillance systems [4]. Epidemiological surveillance was defined as ongoing and systematic collection, analysis, and interpretation of health data in the process of describing and monitoring a health event. The survey included questions about the objective of the surveillance system, the description of the health event under surveillance (case definition), the population under surveillance, the period of data collection, who was responsible for case reporting (sources of information) and a flow chart describing the system. We also asked how often the data were analysed and fed back to the reporting sources, and for the estimated costs of the toxoplasmosis surveillance system.

The usefulness of a given surveillance system was evaluated according to the following criteria:

- simplicity (ease of operation), flexibility (adaptability to changing information needs or operating conditions) and acceptability (cooperation of people on whom the system depends) based on the number and qualification of the reporting sources;

- sensitivity (proportion of cases detected by the system) and representativeness (the ability to describe the distribution of cases over time and in the population) based on the qualification of the reporting sources and on the figures available from the surveillance systems;

- timeliness (delay between steps in the system) based on the frequency of analysis and reports distribution.

\section{F I G U R E}

Different surveillance systems for toxoplasmosis in Europe.

Eurotoxo, 2007

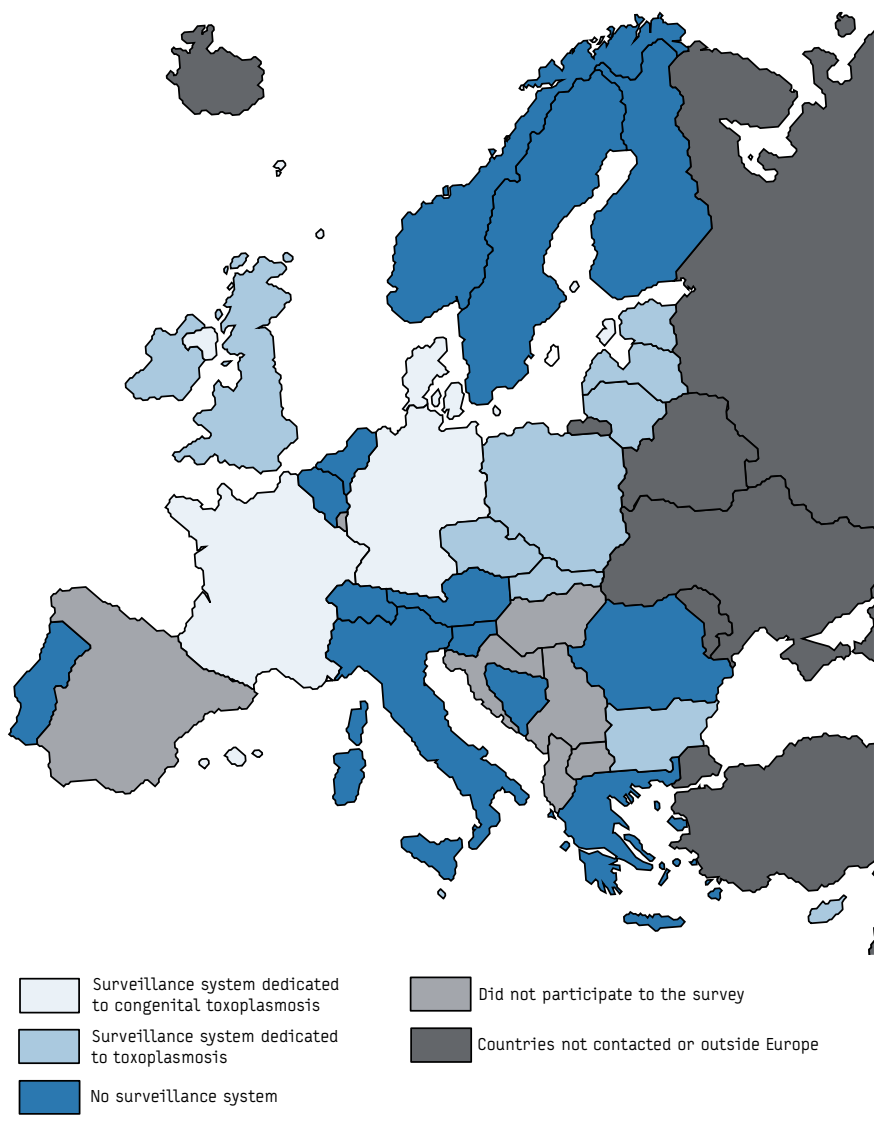

These criteria are described in the US CDC's guidelines (http:// www.cdc.gov/mmwr/preview/mmwrhtml/00001769.htm) [4,5].

Results

We received responses from 28 of 35 countries. Seven countries (Albania, Luxembourg, Croatia, Hungary, the Former Yugoslav Republic of Macedonia, Serbia-Montenegro and Spain) did not send a response at all. Information on Denmark and France was updated in July 2007.

Of the 28 countries that responded, 12 did not have a surveillance system for toxoplasmosis (congenital or not). The 16 countries that did report to have a system for the epidemiological surveillance of toxoplasmosis in place, are almost all situated in central or eastern Europe (Table 2; Figure). Poland has the oldest surveillance system (dating from 1966), while the most recent systems are in Cyprus, Ireland and Malta (dating from 2004).

Only four countries operate surveillance specifically for congenital toxoplasmosis: Denmark, France, Italy and Germany.

In Denmark, a nationwide neonatal screening programme based on neonatal Guthrie card testing for toxoplasma-specific IgM was implemented in 1999 but discontinued on 31 July, 2007 (Petersen E; personal communication). The Danish National Health Board found insufficient evidence that treatment for toxoplasmosis was effective, neither in preventing later attacks of ocular toxoplasmosis in children born without ocular lesions nor in preventing further attacks in children born with ocular lesions [6]. In case of a positive Guthrie result, peripheral blood samples were taken from the newborn and the mother and analysed for IgM, IgA and IgG profiles. The epidemiological surveillance system was based on this screening programme and therefore included all infants with congenital toxoplasmosis, whether or not they had clinical manifestations. Surveillance and all laboratory analyses were coordinated by Statens Serum Institut in Copenhagen.

In France, a surveillance system for congenital toxoplasmosis was initiated in May 2007 which lies in the area of responsibility of the French National Institute of Public Health (Institut national de Veille Sanitaire; InVS) and the National Reference Centre for Toxoplasmosis (CNR toxoplasmose). The surveillance includes foetuses, newborns and children until the age of one year. Congenital toxoplasmosis cases are notifiable and defined as:

- Detection of $T$. gondii in body tissues or fluids by polymerase chain reaction (PCR), inoculation of mice, cell culture or immunocytochemistry;

- Detection of specific IgM or IgA antibodies;

- Neosynthesis of specific IgG, IgM or IgA antibodies;

- Stable specific IgG titres until after the age of one month;

- Persistently stable specific IgG titres until the age of one year.

Cases are notified by laboratories qualified for antenatal or postnatal diagnosis.

In Germany, congenital toxoplasmosis cases have been notifiable since 2001, when a nationwide surveillance system was implemented under the Protection Against Infection Act. The case definition of congenital toxoplasmosis is based on at least one of the following criteria:

- Demonstration of T. gondii in body tissues or fluids;

- Detection of specific IgM or IgA antibodies; 


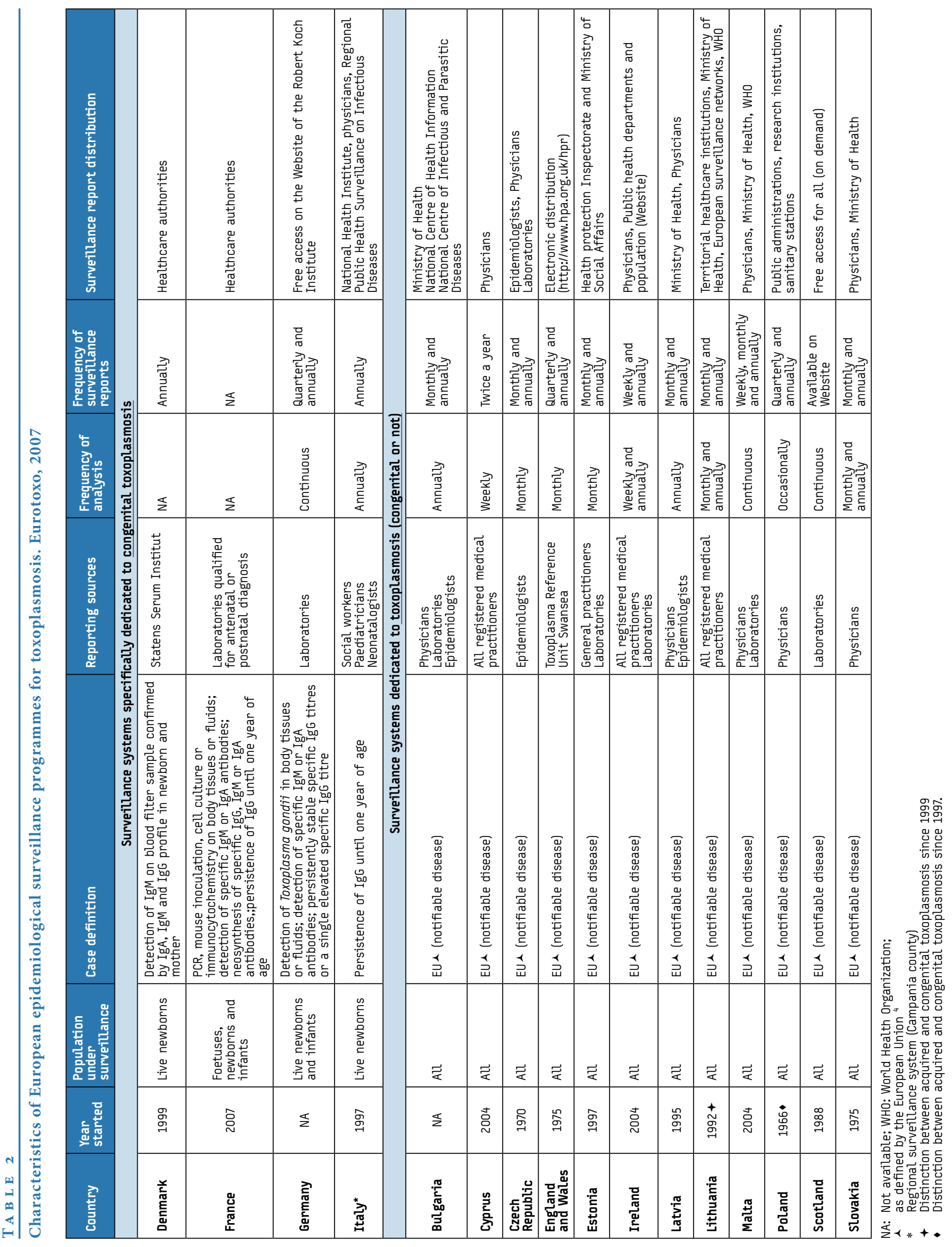


- Persistently stable specific lgG titres or a single elevated specific lgG-titre.

Laboratories report anonymised cases to the Robert Koch institute in Berlin. Part of the data can be accessed at http:// www3.rki.de/SurvStat/QueryForm.aspx. Quarterly summaries and yearly reports are also published [7].

In Italy, surveillance is confined to a regional programme in the Campania region, which has been running since 1997 . The population under surveillance are living newborn babies. A case of congenital toxoplasmosis in defined as the persistence of specific IgG antibodies until the age of one year. Cases are reported by social workers, paediatricians and neonatalogists. Information about toxoplasmosis primary infection among pregnant women is collected retrospectively on medical records, and information about congenital toxoplasmosis and complications among congenitally infected children are collected prospectively. The creation of a nationwide surveillance system is still being debated.

In the 12 other countries (Bulgaria, Cyprus, Czech Republic, England and Wales, Estonia, Ireland, Latvia, Lithuania, Malta, Poland, Scotland, and Slovakia, see Table 2), the health event under surveillance is toxoplasmosis (congenital or not), as defined by the European Union (symptomatic toxoplasmosis cases serologically confirmed) [8]. It is considered a notifiable disease and subject to continuous data collection (Table 2). Cases are reported by physicians, epidemiologists, or laboratories. Several sources of reporting contribute to the systems, except in Cyprus, Lithuania, Poland and Slovakia, where the physicians are the only health professionals to report cases, and in the Czech Republic and Scotland, where cases are declared only by epidemiologists and laboratories, respectively.

All 16 surveillance systems analyse the data regularly (from daily to annually). The reports are sent to the health authorities weekly to annually.

Only two countries were able to provide data about the costs of the system. In Italy, the global cost of the regional pilot programme is estimated to be 68,000 Euros a year for 67,000 to 70,000 live births. In Denmark, the cost of the nationwide surveillance system was estimated to be 600,000 Euros a year.

\section{Discussion}

Our study provides detailed, up-to-date information on systems implemented for the surveillance of toxoplasmosis (congenital or not) in 28 European countries. We have identified a high degree of heterogeneity.

12 countries do not have any surveillance system for toxoplasmosis in place. In 12 countries, the event under surveillance was symptomatic toxoplasmosis. Five of those countries did not provide details about the qualification of the physicians who reported the information. In the field of toxoplasmosis, gynaecologists, ophthalmologists, paediatricians or neurologists are able to diagnose toxoplasmosis at different stages of the disease. Therefore, it is important that all those specialists take part in the surveillance process. However, toxoplasmosis is a notifiable disease in all those countries, and we assume that all registered medical practitioners are involved in the surveillance system.
Denmark, France, Germany, and Italy (the latter only at regional level), are the only participating European countries who have implemented a surveillance system that is specifically dedicated to congenital toxoplasmosis and that is able to detect symptomatic as well as asymptomatic cases. Systems which survey symptomatic toxoplamosis in the general population are of least interest because it is impossible to distinguish congenital from acquired toxoplasmosis without data on the serological status during pregnancy or at birth [9]. Furthermore, the vast majority of acquired toxoplasmosis infections in healthy individuals are benign and the proportion of asymptomatic cases is estimated to be 70\% [10-13].

Differences in the structure of these four specific surveillance systems may be responsible for differences in their usefulness. We consider the surveillance system in Denmark to be simpler than those in Italy, Germany, and France. Centralised analysis like in Denmark and France also increases the acceptability as the system relies on professionals specifically dedicated to the system, contrary to the systems in Italy and Germany where the tasks are divided between health professionals and laboratories. The Danish surveillance system could also be considered the most flexible, because of its centralised approach, which allows for changes to be implemented in only one place, should they become necessary.

In Denmark, the surveillance system was linked to a nationwide systematic neonatal screening [14]. The sensitivity and the representativeness of this system could thus be considered higher than in Germany where the surveillance system is suffering from an underestimation of the number of congenital toxoplasmosis cases. Data on the number of congenital toxoplasmosis cases detected by the two surveillance systems were available for 2001 and 2002. In Germany, 38 cases were reported 2001 and 18 in 2002 (http:// www3.rki.de/SurvStat/QueryForm.aspx) among a population of 82 million inhabitants, compared to 19 cases in 2001 and 13 in 2002 in Denmark (5.4 million inhabitants) [14]. According to these data, the estimated frequency of congenital toxoplasmosis is ten-fold lower in Germany than in Denmark. Based on what is known about the geographical variation of the burden of congenital toxoplasmosis, this is unlikely.

In Italy, congenital toxoplasmosis cases are declared by social workers, paediatricians and neonatalogists. It is well known that passive reporting by physicians only captures a fraction of cases, most often only the most serious ones $[15,16]$.

Overall, we consider the epidemiological surveillance system that was implemented in Denmark be the most useful. However, it was discontinued in July 2007.

A European survey was conducted within the EUROTOXO initiative to describe the national public health policies and routine programmes to prevent congenital Toxoplasmosis [17]. One of the fundamental criteria to evaluate the efficiency of such programmes is the frequency of the prevented disease. Some countries did not define congenital toxoplasmosis as a public health issue and consequently have not implemented a prevention programme or surveillance system.

Several countries that do not have a congenital toxoplasmosis prevention policy have nevertheless defined congenital toxoplasmosis as a public health issue and implemented a surveillance system. But of these countries only Germany has implemented a system specifically dedicated to congenital toxoplasmosis. 
Austria, Denmark, France, Italy, Lithuania and Slovenia have defined congenital toxoplasmosis as a public health issue and implemented a national systematic prevention programme [17]. Among these six countries, Denmark and France are the only countries where a specific and exhaustive surveillance system of congenital toxoplasmosis was implemented. However, screening and surveillance in Denmark were stopped in July 2007 and in France has only existed since May 2007, 29 years after the implementation of the national screening programme.

In the absence of a dedicated surveillance system, data on the burden of a disease can be obtained only through ad hoc epidemiological surveys. A systematic review of the published data on the burden of congenital toxoplasmosis was conducted by the EUROTOXO study group in 2005 [18]. The main results of this review were the following: Firstly, the prevalence of toxoplasmosis among pregnant women (the reservoir of congenital toxoplasmosis) decreases over the years, as previously reported. Due to limited available data, other epidemiological parameters such as incidence of seroconversion in susceptible pregnant women or incidence of complications among congenitally infected children cannot be analysed in detail. Such accurate data on the trends of diseases can only be obtained through continuous data collection such as surveillance systems.

Secondly, published data on the burden of congenital toxoplasmosis in Europe are limited, in terms of both quantity and quality. In fact, the vast majority of surveys evaluated by the group were not representative, in particular with respect to rare events such as the incidence of complications among congenitally infected children. For these estimates to be sufficiently precise, children were recruited in specialised centres. Such representative estimates could be improved by systematic data collection, for example as part of a surveillance system.

Nevertheless, periodic snapshot surveys based on consistent reporting definitions can also be an effective way of determining the burden of congenital toxoplasmosis. This is the approach used in the United Kingdom for symptomatic toxoplasmosis in children through the British Paediatric Surveillance Unit and the British Ophthalmic Surveillance Unit [9].

Few countries in Europe have implemented specific surveillance systems in accordance with their prevention policies regarding congenital toxoplasmosis. The epidemiological surveillance of congenital toxoplasmosis needs to be improved in order to determine the true burden of disease and assess the need for and effectiveness of existing prevention programmes.

\section{Acknowledgements}

The authors would like to thank Alain Moren (EPIET training programme coordinator) and Hélène Therre (Eurosurveillance Monthly editor) for their help in contacting the European correspondents.

EUROTOXO is a joint initiative of the Institute of Child Health (London, UK), the Staten Serum Institute (Copenhagen, Denmark), and the Institute of Public Health, Epidemiology and Development (Bordeaux, France). The EUROTOXO Group was financed by the European Commission (Contract No.QLG4-CT-2002-30262) and worked from 2002-2005.

The EUROTOXO Group was composed as follows (by alphabetical order, except for chairs):
Steering committee: Roger Salamon, Institute of Public Health, Epidemiology and Development (ISPED), Bordeaux, France (Chair): Leiv S. Bakketeig (University of Southern Denmark, Denmark), Gérard Bréart (INSERM U-149, Paris, France), Wilma Buffolano (Universita Frederico II, Naples, Italy), Geneviève Chêne (INSERM U-593, Bordeaux, France), Birgitta Evengard (Karolinska Institute, Huddinge Hospital, Sweden), Ruth Gilbert (Institute of Child Health, London, UK), Michael Hayde (University Children's Hospital, Vienna, Austria), Eskild Petersen (Staten Serum Institute, Copenhagen, Denmark), François Peyron (Hôpital de la CroixRousse, Lyon, France), Aniki Rothova (Academisch Ziekenhuis Utrecht, Utrecht, The Netherlands), L. Rachid Salmi (ISPED, Bordeaux, France), Babill Stray-Pedersen (Institute of General Practice and Community Medicine, University of Oslo, Oslo, Norway), Philippe Thulliez (Institut de Puériculture, Paris, France).

Scientific secretariat: L. Rachid Salmi, ISPED, Bordeaux, France (Chair), Antoine Bénard (INSERM U-593, Bordeaux, France), Ruth Gilbert (Institute of Child Health, Londres, UK), Valériane Leroy (INSERM U-593, Bordeaux, France), Eskild Petersen (Staten Serum Institute, Copenhagen, Denmark), Rodolphe Thiébaut (INSERM U-593 and U-875, Bordeaux, France).

Scientific Secretariat collaborators: Hélène Bricout (INSERM U593, Bordeaux, France), Sabrina Di-Costanzo (INSERM U593, Bordeaux, France), Sandy Leproust (INSERM U593, Bordeaux, France).

Panel 1: L. Rachid Salmi, ISPED, Bordeaux, France (Chair). Antoine Bénard (France), Christine Binquet (France), Michel Cot (France), Catherine De Vigan (France), Marianne Forsgren (Sweden), Justus Garweg (Switzerland), Dorota Nowakowska (Poland), Stefania Salmaso (Italy), Alessandra Sensini (Italy), Rudiger Von Kries (Germany), Anton Van Loon (The Netherlands). Panel 2: Rodolphe Thiébaut, INSERM U-593 and U-875, Bordeaux, France (Chair), Ole Andersen (Denmark), Alain Berrebi (France), Antoine Brézin (France), Bruno Charpiat (France), Francis Derouin (France), Uwe Gross (Germany), François Kieffer (France), Philippe Lepage (Belgium), Laurent Mandelbrot (France), Valeria Meroni (Italy), Maarten Postma (The Netherlands), Miles Stanford (UK).

Panel 3: Valériane Leroy, INSERM U-593, Bordeaux, France (Chair), Antony Ades (UK), Marie-Laure Dardé (France), Anne Eskild (Norway), Christos Hadjichristodoulou (Greece), Pal Jenum (Norway), Monique Kaminski (France), Babak Khoshnood (France), Jean-François Korobelnik (France), Bogumila Milewska-Bobula (Poland), Pierre-Alain Raeber (Switzerland), Christoph Rudin (Switzerland), Isabelle Villena (France).

External experts: Amélie Daveluy, Annie Fourrier-Réglat, François Goffinet, Jérôme Harambat, Françoise Haramburu, Paul Perez, Martine Wallon.

Secretariat, documentation and editorial support: Erica L. Gollub, Evelyne Mouillet, Karine Surlanne, Hooi-Kuan Tan.

\section{References}

1. Salmi LR, Mathoulin S, Perez P, Lawson-Ayayi S. [Screening and early detection in blood transfusion: when are they indicated?] Transfus Clin Biol. 1997;4(4):417-27. [In French].

2. Wilson JMG, Jungner G. Principles and practice of screening for disease. Public Health Papers 34. World Health Organization. Geneva;1968.

3. Gilbert R, Dezateux C. Newborn screening for congenital toxoplasmosis: feasible, but benefits are not established. Arch Dis Child. 2006:91(8):629-31.

4. Centers for Disease Control and Prevention. Guidelines for evaluatin surveillance systems. MMWR Morb Mortal Wkly Rep. 1988;37(S-5):1-18. Available from: http://www.cdc.gov/mmwr/preview/mmwrhtml/00001769.htm

5. Churchill R, Teutsch S. Principles and practice of public health surveillance. New York:0xford University Press;2000.

6. SYROCOT (Systematic Review on Congenital Toxoplasmosis) study group, Thiébaut R, Leproust S, Chêne G, Gilbert R. Effectiveness of prenatal treatment for congenital toxoplasmosis: a meta-analysis of individual patients' data. Lancet. 2007:369(9556):115-22. 
7. Robert Koch Institute. Infektionsepidemiologisches Jahrbuch meldepflichtiger Krankheiten. Available from: http://www.rki.de/cln_048/nn_205772/sid_5FE63EB 7B81740881D8087A454C655D2/ nsc_true/DE/Content/Infekt/Jahrbuch/jahrbuch node.html?_nnn=true

8. European Union. Commission decision of 19 March 2002 laying down case for reporting communicable diseases to the Community network under Decision No 2119/98/EC of the European Parliament and of the Council. OJEC L86/58, 3.4.2002. Official Journal of the European Communities. 2002. Available from: http://eurlex.europa.eu/LexUriServ/site/en/0j/2002/l_086/l_08620020403en00440062.pdf

9. Gilbert R, Tan HK, Cliffe S, Guy E, Stanford M. Symptomatic toxoplasmosis in childhood in the UK. Arch Dis Child. 2006;91(6):495-8.

10. Mawhorter SD, Effron D, Blinkhorn R, Spagnuolo PJ. Cutaneous manifestations of toxoplasmosis. Clin Infect Dis. 1992;14(5):1084-8.

11. Montoya JG, Liesenfeld 0. Toxoplasmosis. Lancet. 2004;363(9425):1965-76.

12. McAuley J, Boyer KM, Patel D, Mets M, Swisher C, Roizen N, et al. Early and longitudinal evaluations of treated infants and children and untreated historical patients with congenital toxoplasmosis: the Chicago Collaborative Treatment Trial. Clin Infect Dis. 1994;18(1):38-72.

13. Binquet C, Wallon M, Quantin C, Kodjikian L, Garweg J, Fleury J, et al. Prognostic factors for the long-term development of ocular lesions in 327 children with congenital toxoplasmosis. Epidemiol Infect. 2003;131(3):131:1157-68.

14. Schmidt DR, Hogh B, Andersen O, Fuchs J, Fledelius H, Petersen E. The national neonatal screening programme for congenital toxoplasmosis in Denmark: results from the initial four years, 1999-2002. Arch Dis Child. 2006;91(8):661-5.

15. Vogt RL, LaRue D, Klaucke DN, Jillson DA. Comparison of an active and passive surveillance system of primary care providers for hepatitis, measles, rubella, and salmonellosis in Vermont. Am J Public Health. 1983;73(7):795-7.

16. Marier R. The reporting of communicable diseases. Am J Epidemiol. 1977;105(6):587-90.

17. Leroy V, Raeber PA, Petersen E, Salmi LR, Kaminski M, Villena I, et al. for the Eurotoxo Group (Panel 3). National public health policies and routines programs to prevent congenital Toxoplasmosis, Europe, 2005 [Unpublished report]. Bordeaux (France): The Eurotoxo Group;2005. Available from: http:// eurotoxo.isped.u-bordeaux2.fr/WWW_PUBLIC/DOC/EUROTOXO_R1_P3_European_ national_policies_Dec2005.pdf

18. Bénard A., Salmi LR, for Panel 1 of the Eurotoxo Group. Systematic review on the burden of congenital toxoplasmosis in Europe [Unpublished report]. Bordeaux (France): The Eurotoxo Group;2005. Available from: http://eurotoxo. isped.u-bordeaux2.fr/WWW_PUBLIC/DOC/EUROTOXO_Panel_1_Sytematic_review on_the_burden_of_CT_30-01-2006.pdf

This article was published on 10 April 2008.

Citation style for this article: Bénard A, Petersen E, Salamon R, Chêne G, Gilbert R, Salmi LR, for the European Toxo Prevention Study Group (EUROTOXO). Survey of European programmes for the epidemiological surveillance of congenital toxoplasmosis. Euro Surveill. 2008;13(15):pij=18834. Available online: http://www.eurosurveillance.org/ ViewArticle.aspx?ArticleId $=18834$ 